\title{
Critical reappraisal of risk factors for occurrence of hepatocellular carcinoma in patients with hepatitis $C$ virus
}

This article was published in the following Dove Press journal:

Hepatic Medicine: Evidence and Research

29 March 20II

Number of times this article has been viewed

\author{
Savino Bruno' \\ Daniela Savojardo' \\ Piero L Almasio ${ }^{2}$ \\ Mario U Mondelli ${ }^{3}$ \\ 'Liver Unit, Department of Medicine, \\ Azienda Ospedaliera Fatebenefratelli \\ e Oftalmico, Milan, Italy; ${ }^{2}$ Unità \\ Complessa di Gastroenterologia \\ ed Epatologia, University of Palermo, \\ Palermo, Italy; ${ }^{3}$ Struttura Complessa \\ Laboratori di Infettivologia, \\ Dipartimento di Malattie Infettive, \\ Fondazione IRCCS Policlinico San \\ Matteo e Università di Pavia, Pavia, Italy
}

\begin{abstract}
More than one and half of current cases of hepatocellular carcinoma in the US, Europe, and Japan are attributable to hepatitis $\mathrm{C}$ virus (HCV) infection. $\mathrm{HCV}$ is also the primary cause of death in patients with HCV-related cirrhosis, with annual incidences of $0.5 \%-5 \%$ in Europe and $4 \%-10 \%$ in Asia. Screening is based on serum alpha-fetoprotein determination and liver ultrasound scan, but the sensitivity of the former is far less than optimal, and screening intervals are still poorly defined for the latter. Risk factors related to the host or environment, or both, appear to be more relevant than viral factors, such as HCV genotype, in determining disease progression to cirrhosis and cancer, and include age, male gender, severity of liver disease at presentation, coinfection with hepatitis B virus or human immunodeficiency virus, and alcohol abuse. Early liver transplantation in selected cases can be curative, but most patients are not eligible for liver grafting and are treated with locoregional ablative therapies, after which recurrence is common. Recently, orally available inhibitors of the vascular endothelial growth factor receptor have shown a significant, albeit modest, increment of survival in patients with advanced hepatocellular carcinoma, thus paving the way for modern molecular approaches to treatment of this highly malignant tumor.
\end{abstract}

Keywords: hepatocellular carcinoma, hepatitis C virus

\section{Introduction}

Development of hepatocellular carcinoma usually occurs after two or more decades of hepatitis $\mathrm{C}$ virus (HCV) infection, and the increased risk is largely restricted to patients with cirrhosis or advanced fibrosis ${ }^{1}$ (see Figure 1). The rate of development of hepatocellular carcinoma in HCV-related cirrhosis ranges between 3 and 7.1 per year in Europe and Japan, respectively, with hepatitis B virus (HBV) coinfection and alcohol intake being significant cofactors and increasing the incidence by approximately 2-4-fold. ${ }^{2}$ Surveillance programs in well selected cirrhotic patients may allow the recognition of liver tumors at early stages, when potentially curative therapies able to increase life expectancy are feasible. ${ }^{3}$ In fact, it has been clearly shown that when hepatocellular carcinoma is diagnosed by screening procedures, patients may have better survival than those with symptomatic disease at presentation, ${ }^{2}$ despite no reliable data to support a clear effect in reducing cancer-related deaths. ${ }^{4}$ It has been estimated that surveillance in cirrhotic patients is cost-effective in that it increases survival for at least 3 months, with a cost per year of life saved below $\$ 50,000 .^{5}$ Such a scenario is achieved in cirrhosis of any etiology when the risk of hepatocellular carcinoma is $1.5 \%$ per year or greater, according to the American Association for the Study of the Liver guidelines. ${ }^{6}$ Whether patients with Stage 3 fibrosis should also be offered
Correspondence: Mario U Mondelli S.C. Laboratori di Infettivologia, Dipartimento di Malattie Infettive, Fondazione IRCCS Policlinico San Matteo, p.le Golgi 19, 27100, Pavia, Italy Tel +390382502639

Fax +390382526450

Email mario.mondelli@unipv.it 


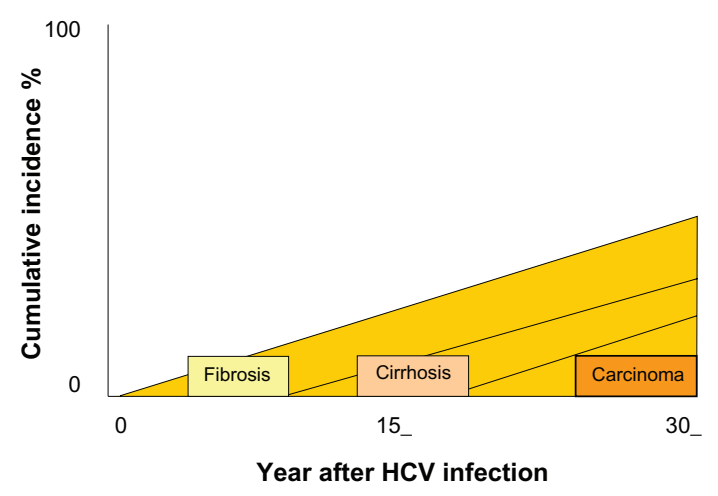

Figure I

screening is not clear, because the risk of hepatocellular carcinoma in these patients is much lower and may not exceed the $1.5 \%$ per year mark. ${ }^{2}$

\section{Screening for hepatocellular carcinoma}

Growth rates of subclinical cancer may be very different from tumor growth rates in clinically observed cancers. It has been well documented that the sensitivity and specificity of a diagnostic test can change with the cancer stage, and thus are likely to be different in preclinical cancers. ${ }^{2}$ Alpha-fetoprotein has been used as both a serological marker of hepatocellular carcinoma and in combination with ultrasound for hepatocellular carcinoma screening. ${ }^{2}$ Several reports have also shown an elevated alpha-fetoprotein level to be a risk factor for the development of hepatocellular carcinoma in patients with $\mathrm{HCV}$ infection. ${ }^{6,7}$ In a recent study $^{8}$ among patients infected with $\mathrm{HCV}$, including not only those with cirrhosis but also those with chronic hepatitis, alpha-fetoprotein levels were found to be an independently associated risk factor for hepatocellular carcinoma, regardless of fibrosis stage. Of particular note, not only patients with high alpha-fetoprotein levels ( $\geq 20 \mathrm{ng} / \mathrm{mL}$ ) but also those with even slightly elevated alpha-fetoprotein levels $(6-20 \mathrm{ng} / \mathrm{mL})$ had an increased risk of developing hepatocellular carcinoma. In contrast, alpha-fetoprotein levels $<6 \mathrm{ng} / \mathrm{mL}$ indicate a low risk of development of hepatocellular carcinoma, irrespective of liver fibrosis stage. However, it should be noted that alpha-fetoprotein levels are associated with advanced stages of fibrosis in patients with HCV infection without evidence of hepatocellular carcinoma. ${ }^{9,10}$ Receiver operating curve analysis of alpha-fetoprotein used as a diagnostic test suggests that a value of $\geq 20 \mathrm{ng} / \mathrm{mL}$ provides the optimal balance between sensitivity and specificity. ${ }^{11}$ However, using this cutoff level, sensitivity is only $60 \%$. It is clear that more hepatocellular carcinomas would be identified by reducing the cutoff value, but at the cost of a progressive increase in the false-positive rate. ${ }^{2}$ Therefore, alpha-fetoprotein is an inadequate screening test for detection of hepatocellular carcinoma $^{12}$ and, consequently, its use for this purpose has been discontinued. ${ }^{6,13}$ However, it can be used to identify high-risk patients at the initial evaluation, and its use for periodic assessment during follow-up is appropriate in everyday clinical practice.

Liver ultrasound is the most widely used technique for hepatocellular carcinoma screening. It has been reported to have a sensitivity of $65 \%-80 \%$ and a specificity greater than $90 \%$ when used as a screening test. ${ }^{2,14}$ The major drawbacks of this approach are that it is highly dependent upon operator skill and is difficult to perform in obese subjects. Combined use of alpha-fetoprotein and ultrasound increases detection rates, but also has increased financial costs and false-positive rates. ${ }^{2,15}$ The guiding principle should be that the best locally available screening test should be chosen and used regularly.

The evidence showing that optimal screening intervals should be determined by tumor growth rate and not by degree of risk implies that screening intervals need not be reduced for those patients who have a higher risk of hepatocellular carcinoma. Survival appears to be similar for patients screened at six-monthly or 12-monthly intervals, ${ }^{16}$ and the likelihood of detecting hepatocellular carcinoma as a single nodule (as opposed to a multinodular tumor) has been shown to be similar when using six-month and 12-month screening intervals. $^{17}$

\section{Natural history and clinical presentation}

The features of hepatocellular carcinoma may differ according to the presence or absence of underlying cirrhosis. The mean age is usually older, and male prevalence is more pronounced than in those without cirrhosis in hepatocellular carcinoma patients in most studies. ${ }^{18,19}$ Abdominal pain or discomfort localized to the right upper quadrant is the most common presenting symptom in noncirrhotic patients, whereas, in individuals with cirrhosis, the majority of cancers are asymptomatic and diagnosed incidentally by ultrasound examination. ${ }^{20}$ Liver function tests (albumin, bilirubin) are more commonly and more markedly altered in cirrhotic patients with hepatocellular carcinoma. ${ }^{20}$

The natural history of compensated cirrhosis caused by chronic HCV was assessed in a subgroup of 136 of 384 untreated patients followed for a mean of 6.8 years in 
a collaborative European study. ${ }^{21}$ In this cohort of Caucasian patients, the five-year cumulative risk for hepatocellular carcinoma was $10 \%$, and the mean interval between time of diagnosis of cirrhosis and occurrence of hepatocellular carcinoma was five years. Median age at diagnosis of hepatocellular carcinoma was 63 years. ${ }^{22}$ Approximately half of the patients who developed hepatocellular carcinoma did not experience hepatic decompensation before or at the time of diagnosis of liver cancer, indicating that hepatocellular carcinoma arising in the clinical setting of compensated cirrhosis is generally clinically silent. ${ }^{22}$

\section{Incidence of hepatocellular carcinoma in HCV patients}

Hepatocellular carcinoma affects approximately half a million persons each year worldwide, making it the fifth most common malignancy in men and the ninth most common in women, ${ }^{2,23}$ and it is the leading cause of death in people with cirrhosis. ${ }^{4}$ Hepatocellular carcinoma is a well recognized complication of cirrhosis, regardless of etiology, although the risk of malignancy differs according to the underlying cause of liver damage. ${ }^{24}$ The highest incidence of hepatocellular carcinoma is seen in China (about 100 per 100,000 population), where the major component of the attributable risk is related to chronic HBV infection (range 40\%-90\%). ${ }^{2}$

The incidence of hepatocellular carcinoma and its absolute mortality is increasing in Europe and the US (generally considered to be low-incidence regions, ie, 2.6 to 9.8 per 100,000 population), and is currently the leading cause of death in patients with cirrhosis. ${ }^{2,25}$

A study from the Department of Veterans Affairs found a three-fold increase in HCV-related hepatocellular carcinoma, whereas the rate of hepatocellular carcinoma associated with HBV or alcohol-induced liver disease and idiopathic cirrhosis remained stable. ${ }^{2,26}$ The cause of this increase remains uncertain, but a possible explanation is that the medical management of nonhepatocellular carcinoma-related complications of cirrhosis, such as prevention and treatment of variceal bleeding and management of ascites, has improved, leading to longer survival of patients with cirrhosis, who in turn are at greater risk over time of developing hepatocellular carcinoma. ${ }^{25}$ To a limited extent, these trends may be related to improvements in the screening and/or diagnosis of hepatocellular carcinoma, ${ }^{23}$ such as serial serum alpha-fetoprotein measurements, ultrasound, and computed tomography.

The incidence of hepatocellular carcinoma is age-related, but the age distribution varies in different local regions of the world. The pattern suggests that, with urbanization, the median age of onset is shifted to older age groups (exposure occurring at younger ages in high incidence countries). ${ }^{2}$ Because the epidemiology of chronic HCV indicates that, in many countries, peak infection rates occurred prior to 1980 , it is likely that the trend towards an increasing incidence of hepatocellular carcinoma will continue. In addition, in many countries, emigration from areas of high hepatitis prevalence will also result in an increase in hepatocellular carcinoma related to both $\mathrm{HBV}$ and $\mathrm{HCV}^{2}$ In Japanese studies, the summary hepatocellular carcinoma incidence rate is 1.8 per 100 person-years in subjects with chronic $\mathrm{HCV}$ without cirrhosis at diagnosis, and 7.1 in those with compensated cirrhosis, establishing a four-fold higher risk of hepatocellular carcinoma in persons with cirrhosis than for those with chronic hepatitis. ${ }^{27,28}$ In Europe and the US, the overall hepatocellular carcinoma incidence rate in patients with HCV-related cirrhosis is 3.7 per 100 person-years, ${ }^{22,29}$ whereas no estimate can be calculated for persons with chronic $\mathrm{HCV}$ without cirrhosis because of the lack of hepatocellular carcinoma cases in the only study performed. ${ }^{30}$ The five-year cumulative risk for hepatocellular carcinoma in patients with cirrhosis is $17 \%$ in Europe and the US, and 30\% in Japan.

Once HCV-related cirrhosis is established, the annual rate of hepatocellular carcinoma is $1 \%-4 \%$ (higher than those reported for HBV and alcoholic cirrhosis). ${ }^{31,32}$ In Asia, the annual incidence of hepatocellular carcinoma in HCV-related cirrhosis is reported to be $4 \%-10 \%$, whereas in European studies the reported annual incidence is $0.5 \%-5 \%$ in comparable subjects. ${ }^{33}$

Reports of hepatocellular carcinoma occurring in subjects with bridging fibrosis without definite cirrhosis also exist, and, among patients with hepatocellular carcinoma but without cirrhosis, HCV infection accounts for 3\%-54\% of cases. These data are in agreement with previous findings showing persistence and replication of $\mathrm{HCV}$ genomes in cancerous and noncancerous liver tissue of case series without cirrhosis but with some degree of fibrosis and inflammation, ${ }^{34}$ indicating that the mere existence of chronic liver disease is a potential risk for the development of hepatocellular carcinoma. ${ }^{25}$

Chronic necroinflammation and generation of reactive oxygen species can induce chromosomal mutations and eventually trigger malignant transformation. Another possible explanation for hepatocellular carcinoma developing in association with chronic liver disease is underestimation of the degree of fibrosis/cirrhosis on liver biopsy resulting from sampling error. ${ }^{33}$ This report raises the question of whether such patients should undergo hepatocellular 
carcinoma surveillance, as is recommended for persons with established cirrhosis.

\section{Risk factors for hepatocellular carcinoma}

It should be taken into account that cirrhosis and hepatocellular carcinoma share the same risk factors, and therefore the identification of predictors independently associated with the development of the tumor is particularly hard. ${ }^{35}$ In $\mathrm{HCV}$-infected patients, factors related to the host or environment, or both, appear to be more relevant than viral factors in determining the progression of HCV infection to cirrhosis (Table 1). These factors include older age, older age at time of HCV infection, male gender, heavy alcohol intake (more than $50 \mathrm{~g}$ /day), HBV-HCV or HCV-human immunodeficiency virus (HIV) coinfection, and transfusion-related mode of $\mathrm{HCV}$ acquisition. ${ }^{23}$

\section{Host-related factors}

Independent factors associated with progression to hepatocellular carcinoma are older age at diagnosis $(>55$ years, 2-4-fold increased risk) and male gender (2-3-fold increased risk). Men are at higher risk for hepatocellular carcinoma than women, and there is, as yet, no satisfactory explanation for this phenomenon. ${ }^{2}$ Mild elevations in serum bilirubin level and decreased platelet count are also associated with occurrence of hepatocellular carcinoma. ${ }^{22,31}$

Table I Factors affecting progression to hepatocellular carcinoma in hepatitis C-related compensated cirrhosis

\begin{tabular}{ll}
\hline Host-related & \\
Age at diagnosis & Relevant \\
Age at infection & Relevant \\
Male gender & Relevant \\
Severity of liver disease & Relevant \\
at presentation & \\
Comorbidity & \\
Porphyria cutanea tarda & Important (Southern Europe and the US) \\
Iron overload & Controversial \\
Liver steatosis & Growing evidence \\
Diabetes mellitus & Growing evidence \\
Virus-related & \\
Viral genotype & Controversial \\
Viral burden & Insufficient evidence \\
Overt HBV coinfection & Relevant \\
Occult HBV infection & Growing evidence \\
HIV coinfection & Growing evidence \\
External & \\
Alcohol intake & Relevant \\
Smoking & Controversial \\
\hline Abreviations: HBV, hepatis B vir; HCV, hepais C virus HI, huma &
\end{tabular}

Abbreviations: HBV, hepatitis B virus; HCV, hepatitis C virus; HIV, human immunodeficiency virus.
Patients in the EUROHEP cohort could be stratified into four categories according to five-year risk of hepatocellular carcinoma; the risk was relatively low (3\%) for a 50-year-old man having cirrhosis with normal serum levels of bilirubin and platelet counts, but increased to $25 \%$ for a 60 -year-old man having cirrhosis with mild elevation in serum bilirubin levels $(17-51 \mu \mathrm{mol} / \mathrm{L}[1.0-3.0 \mathrm{mg} / \mathrm{dL}])$ and a low platelet count $\left(100-130 \times 10^{9} / \mathrm{L}\left[100,000-130,000 / \mathrm{mm}^{3}\right]\right){ }^{36}$

It has been suggested that the incidence of hepatocellular carcinoma in association with HCV cirrhosis increases only when the platelet count is less than $100 \times 10^{9} / \mathrm{L}$, but this needs to be substantiated. ${ }^{2}$ Various additional factors for hepatocellular carcinoma occurring in all liver disease associated with cirrhosis include a persistently elevated alpha-fetoprotein level, changes on biopsy, such as large cell dysplasia, and an increased labeling index for proliferating cell nuclear antigen or silver staining of the nucleolar organizing region. ${ }^{2}$

A population-based study (in individuals 65 years and older) examining the association between diabetes and hepatocellular carcinoma in the US was performed in $2005,{ }^{37}$ showing diabetes to be an independent risk factor for hepatocellular carcinoma, regardless of the presence of $\mathrm{HCV}, \mathrm{HBV}$, genetic hemochromatosis, alcoholic liver disease, or nonspecific cirrhosis (2-3-fold increase in risk of hepatocellular carcinoma). In this study, the statistical evidence of a significant interaction was found only between diabetes and HCV. Similar data were obtained from Danish and Swedish patients with diabetes alone, as well as in the presence of hepatitis, cirrhosis, alcoholrelated conditions, and other liver disorders. ${ }^{38,39}$ Diabetes, as part of insulin resistance syndrome, has been implicated as a risk factor for nonalcoholic fatty liver disease, including its most severe form, ie, nonalcoholic steatohepatitis, which has been identified as a cause of both cryptogenic cirrhosis and hepatocellular carcinoma. One study found that patients with a longer duration since the onset of diabetes had a greater risk of developing hepatocellular carcinoma compared with patients more recently diagnosed with diabetes. ${ }^{40}$

Both alcohol and HCV cooperate to increase the risk for hepatocellular carcinoma by more actively promoting cirrhosis. Among alcohol drinkers, the risk of hepatocellular carcinoma increased in a linear fashion with a daily intake greater than $60 \mathrm{~g} / \mathrm{day}$, and the presence of HCV had a positive synergistic action, with an additional two-fold increase in the risk over that caused by alcohol alone. ${ }^{41}$ It is less certain whether alcohol consumption may further increase the risk for hepatocellular carcinoma in HCV-related cirrhosis. A systematic review of epidemiological studies has reported that the pattern of hepatocellular carcinoma risk due to 
alcohol intake shows a continuous dose-effect curve without a definite threshold, although for HCV infected subjects a significant increase in hepatocellular carcinoma risk was shown at a level of $40 \mathrm{~g} /$ day, suggesting that even a low alcohol intake cannot be regarded as safe in this population..$^{42}$ Thus, the dose-effect instead of an all-or-none relationship between alcohol intake and hepatocellular carcinoma risk should be explored in prognostic studies of HCV-related cirrhosis. ${ }^{4}$ Finally, genome-wide gene expression arrays have been used by several groups to identify different molecular subclasses of human hepatocellular carcinoma tissue samples. ${ }^{43}$ A recent study from Hoshida et al has shown that a reproducible gene expression signature, present in liver tissue adjacent to formalin-fixed and paraffin-embedded hepatocellular carcinoma tissue, was correlated with survival. ${ }^{44}$ In a different study, they also reported a significant role of mTOR signaling activation in human hepatocellular carcinoma, as well as the antitumoral effect of a dual-level blockade of the mTOR pathway, ie, mTOR blockade decreased tumor growth and extended survival in experimental hepatocellular carcinoma xenograft models.

\section{Viral-related factors}

A recent meta-analysis ${ }^{35}$ performed on 32 studies of patients with liver cirrhosis strongly suggests that HCV genotype $1 \mathrm{~b}$ is associated with the risk of developing hepatocellular carcinoma (almost double the risk of developing hepatocellular carcinoma than those infected with other genotypes), with a positive relative risk ( $95 \%$ confidence interval [CI]) of 1.60 (1.07-2.39). The risk is higher in the early stages of liver disease when compared with patients affected by liver cirrhosis. Several authors have suggested that this association could be due to a role of HCV genotype $1 \mathrm{~b}$ in the early stage of liver disease progression prior to the establishment of liver cirrhosis, ${ }^{45,46}$ with genotype $1 \mathrm{~b}$ playing a major role in carcinogenesis and the development of hepatocellular carcinoma through its association with chronic inflammation, liver cell necrosis, regeneration, and extensive fibrosis. Recent findings ${ }^{47}$ suggest that specific conformational features of the secondary structure of the N-terminus of the NS3 protein, characteristics of certain strains of HCV type $1 \mathrm{~b}$, are associated with an increased risk of hepatocellular carcinoma, thus providing a plausible pathogenetic basis in support of the data obtained from this meta-analysis.

Clinical differences among HCV genotypes and specific host/virus interactions depending on the infecting genotype also exist, as suggested by the association of genotype 2 with mild liver disease ${ }^{48}$ and better responses to antiviral treatment. ${ }^{49,50}$ There are conflicting data as to whether genotype 1 is a risk factor for cirrhosis or hepatocellular carcinoma independent of older age,${ }^{51}$ and it has been suggested that the higher prevalence of these genotypes reported in some studies represents a cohort effect in which older persons (those at greater risk for cirrhosis and hepatocellular carcinoma) were infected at a time when genotype 1 was most prevalent. ${ }^{52}$ A subsequent update of the original study, with a median follow-up of 17 years, ${ }^{53}$ and a meta-analysis ${ }^{35}$ are consistent with genotype 1 being an independent risk factor for tumor development. However, there is agreement that neither viral load nor viral quasispecies play a role in this setting. ${ }^{22}$

Dual infection with HBV and HCV in cirrhotic patients has been linked with an increased risk of hepatocellular carcinoma. A meta-analysis of case-control studies found a synergism between the two viruses with regard to carcinogenesis, the risk being more additive than multiplicative. ${ }^{54}$ In cohort studies among Italian and Chinese patients with cirrhosis, those with $\mathrm{HBV} / \mathrm{HCV}$ coinfection had a 2-6-fold higher risk of developing hepatocellular carcinoma compared with those with monoinfection. ${ }^{55,56}$ Occult HBV infection, ie, absence of hepatitis B surface antigen, but presence of HBV-DNA in serum and/or in liver tissue, can be identified in up to $50 \%$ of anti-HCV-positive patients who develop hepatocellular carcinoma. ${ }^{57}$ Clear evidence that occult $\mathrm{HBV}$ is a risk factor for hepatocellular carcinoma in hepatitis B surface antigen-negative patients derives from the study by Pollicino et al, ${ }^{58}$ showing a higher prevalence of both integrated and free-HBV DNA, associated with low levels of transcription and replication, in liver specimens of anti-HCV-negative hepatocellular carcinoma patients compared with anti-HCV-negative subjects with cirrhosis or chronic hepatitis. Hepatocellular carcinoma seems to occur at a younger age and after a shorter period of HCV infection in subjects coinfected with HIV compared with patients with HCV-related hepatocellular carcinoma but without HIV infection. $^{59}$

Modality of HCV acquisition seems to be an independent predictor of the incidence of cirrhosis and hepatocellular carcinoma in $\mathrm{HCV}$-infected cohorts, ${ }^{23}$ the highest pooled incidence rates for cirrhosis and hepatocellular carcinoma being found in studies involving recipients of blood or blood products who acquired transfusion-associated $\mathrm{HCV}$ (14 and 1 per 1000 person-years, respectively), and in studies of persons with hemophilia, ${ }^{23}$ whereas studies involving community-acquired HCV that included users of injectable drugs had an intermediate weighted pooled incidence (5 and 0 per 1000 person-years, respectively), for cirrhosis 
and hepatocellular carcinoma. These findings suggest that the size of the inoculum may play a role in this setting.

\section{Conclusion}

The rapid increase in rates of hepatocellular carcinoma in the developed world parallels that of the prevalence of chronic HCV infection in the 1960s and 1970s, ${ }^{23,40}$ and is consistent with the natural history of HCV infection. Once cirrhosis is established, hepatocellular carcinoma develops at a yearly rate of $1 \%-4 \%{ }^{21}$ Thus, the incubation period between the onset of HCV infection and the appearance of hepatocellular carcinoma is approximately 2-4 decades. At present, cross-sectional surveys indicate that more than one half of current cases of hepatocellular carcinoma in the US, Europe, and Japan are attributable to HCV infection, and that most patients have cirrhosis. ${ }^{60-62}$

A main problem is that the increase in incidence of hepatocellular carcinoma in the developed world has not been matched by improvement in patient survival. Drugs specifically targeting molecules or genes involved in liver carcinogenesis are being designed, and protein kinase inhibitors represent the largest family of compounds in liver oncology, followed by monoclonal antibodies. In a recent paper by Llovet et al, sorafenib, an oral multikinase inhibitor of the vascular endothelial growth factor receptor, prolonged median survival by nearly three months and time to radiologic progression in patients with advanced hepatocellular carcinoma. ${ }^{63}$ In spite of the small gain in patient survival, this drug is now considered the standard of care for advanced hepatocellular carcinoma. ${ }^{43}$
These results represent a milestone in the treatment of hepatocellular carcinoma and have stimulated the search for similar compounds targeting other molecular alterations (largely displayed by this tumor), in particular, combination therapies are postulated to be a promising approach through synergistic antitumoral effects. ${ }^{43}$ The combination of novel epigenetic drugs or antimicroRNA compounds with small molecules like sorafenib could be a promising new approach in treating this complex tumor. The microRNAs are small RNA molecules with an increasing role in cancer therapy because they can act as oncogenes or tumor suppressor genes, while epigenetic drugs consist of demethylating agents and histone deacetylase inhibitors, and both are able to re-express epigenetically silenced genes (see Table 2 for a survey of molecular therapies in clinical trials for hepatocellular carcinoma).

Hepatocellular carcinoma remains a highly malignant tumor, with average survival rates after clinical onset of less than one year. ${ }^{64}$ The problems with treatment of hepatocellular carcinoma are many, but the major difficulty is that most patients with hepatocellular carcinoma present when the disease is at an advanced stage, by which time the tumor is no longer amenable to resection or ablation. Clearly, the most practical approach to better management of hepatocellular carcinoma is prevention and, barring that, early detection combined with local resection or ablation. Yet even with regular surveillance and early detection followed by resection or ablation, recurrence is common. ${ }^{65}$ For these reasons, liver transplantation has been increasingly used as an approach to management and potential cure of

Table 2 Molecular therapies in clinical trials for hepatocellular carcinoma

\begin{tabular}{|c|c|c|c|c|c|}
\hline Function & Target & Compound & Other agents & Class & Phase \\
\hline \multirow[t]{8}{*}{ Growth factors } & EGFR & Gefitinib Erlotinib & & Small molecule & II \\
\hline & & & & & III \\
\hline & RAF & Sorafenib & $\begin{array}{l}\text { VEGFR, } \\
\text { c-KIT }\end{array}$ & Small molecule & FDA approved \\
\hline & MAP3KI & AZD6244 & & Small molecule & II \\
\hline & Proteosome & Bortezomib & & Small molecule & II \\
\hline & Her2/neu & Lepatinib & EGFR & Small molecule & II \\
\hline & IGFR & IMC-AI2 & & Monoclonal antibody & II \\
\hline & mTOR & Everolimus & & Small molecule & $\mathrm{I} / \mathrm{II}$ \\
\hline \multirow[t]{3}{*}{ Angiogenesis } & VEGFR & Bevacizumab & PDGF, & Monoclonal antibody & III \\
\hline & & Sunitinib & c-KIT & Small molecule & III \\
\hline & PDGFR & Imatinib & c-KIT & Small molecule & II \\
\hline \multirow[t]{2}{*}{ Apoptosis } & TRAIL LI & Mapatumumab & & Monoclonal antibody & $\mathrm{I} / \mathrm{II}$ \\
\hline & BCL-2 & Oblimersen & & ASO & II \\
\hline Cell cycle & CDK & Flavopiridol & & Small molecule & II \\
\hline Histone acetylation & HDAC & LBH589 & & Small molecule & I \\
\hline
\end{tabular}

Abbreviations: ASO, antisense oligodeoxyribonucleotide; BCL, B cell CLL lymphoma; CDK, cycline dependent kinases; HDAC, histone deacetylase; MAP3 KI, mitogenactivated proteine kinase; PDGF, platelet-derived growth factor; RAF, v-raf-I murine leukemia viral oncogene homolog; TRAIL, TNF-related apoptosis-inducing ligand; VEGF, vascular endothelial growth factor; EGF, epidermal growth factor; IGF, insulin-like growth factor. 
hepatocellular carcinoma. ${ }^{66}$ Unfortunately, there continues to be a shortage of livers for transplantation, and allocation of more organs to patients with hepatocellular carcinoma may overwhelm the distribution system.

All of these factors speak of a need for action to promote research that might reverse these trends. The three most appropriate means to accomplish this are prevention, early detection, and the development of novel therapies. Also important for any approach to decreasing the burden of hepatocellular carcinoma is to attain more information on the frequency of this cancer and its clinical presentations, risk factors, and underlying causes. ${ }^{65}$

Hepatocellular carcinoma is almost unique among cancers because the underlying cause can usually be identified for individual patients, in contrast with most other major cancers, for which risk factors can be identified only at a population level.

Finally, a meaningful result in the prevention of hepatocellular carcinoma will be achieved by the treatment of the underlying liver disease, such as antiviral therapies for both $\mathrm{HBV}$ and HCV, the efficacy of which has been reported to be enhanced. The usefulness of studies assessing "-omics" methods to tissue, serum, and DNA samples, focusing on the pathogenesis of malignant transformation during the course of chronic liver disease, developing biomarkers for early-stage hepatocellular carcinoma, defining biological risk factors for hepatocellular carcinoma, and identifying potential targets for molecular-based therapy for hepatocellular carcinoma ${ }^{63}$ represent major challenges for the future.

\section{Disclosure}

The authors report no conflicts of interest in this work.

\section{References}

1. Cabibbo G, Craxì A. Epidemiology, risk factors and surveillance of hepatocellular carcinoma. Eur Rev Med Pharmacol Sci. 2010;14(4): 352-355.

2. Sherman M. Hepatocellular carcinoma: Epidemiology, risk factors and screening. Semin Liver Dis. 2005;25(2):143-154.

3. Llovet JM, Burroughs A, Bruix J. Hepatocellular carcinoma. Lancet. 2003;362(9399):1907-1917.

4. Fattovich G, Llovet JM. Risk factors for hepatocellular carcinoma in HCV-cirrhosis: What we know and what is missing. J Hepatol. 2006; 44(6):1013-1016.

5. Laupacis A, Feeny D, Detsky AS, Tugwell PX. How attractive does a new technology have to be to warrant adoption and utilization? Tentative guidelines for using clinical and economic evaluations. CMAJ. 1992; 146(4):473-481.

6. Bruix J, Sherman M. Management of hepatocellular carcinoma. Practice Guidelines Committee, American Association for the Study of Liver Diseases. Hepatology. 2005;42(5):1208-1236.

7. Colombo M, De Franchis R, Del Ninno E, et al. Hepatocellular carcinoma in Italian patients with cirrhosis. N Engl J Med. 1991;325(10): 675-680.
8. Tateyama M, Yatsuhashi H, Taura N, et al. Alpha-fetoprotein above normal levels as a risk factor for the development of hepatocellular carcinoma in patients infected with hepatitis C virus. $J$ Gastroenterol. 2011;46(1):92-100.

9. Lu LG, Zeng MD, Mao YM, et al. Relationship between clinical and pathologic findings in patients with chronic liver diseases. World $J$ Gastroenterol. 2003;9(12):2796-2800.

10. Di Bisceglie AM, Sterling RK, Chung RT, et al. Serum alpha-fetoprotein levels in patients with advanced hepatitis C: Results from the HALT-C Trial. J Hepatol. 2005;43(3):434-441.

11. Trevisani F, D'Intino PE, Morselli-Labate AM, et al. Serum alphafetoprotein for diagnosis of hepatocellular carcinoma in patients with chronic liver disease: Influence of HBsAg and anti-HCV status. J Hepatol. 2001;34(4):570-575.

12. Sherman M. Alphafetoprotein: An obituary. J Hepatol. 2001;34(4): 603-605.

13. Bruix J, Sherman M, Llovet JM, et al. Clinical management of hepatocellular carcinoma. Conclusions of the Barcelona 2000 EASL Conference. J Hepatol. 2001;35(3):421-430.

14. Pateron D, Ganne N, Trinchet JC, et al. Prospective study of screening for hepatocellular carcinoma in Caucasian patients with cirrhosis. J Hepatol. 1994;20(1):65-71.

15. Zhang B, Yang B. Combined alpha fetoprotein testing and ultrasonography as a screening test for primary liver cancer. J Med Screen. 1999; 6(2): 108-110.

16. Sangiovanni A, Del Ninno E, Fasani P, et al. Increased survival of cirrhotic patients with a hepatocellular carcinoma detected during surveillance. Gastroenterology. 2004;126(4):1005-1014.

17. Santagostino E, Colombo M, Rivi M, et al. A 6-month versus a 12-month surveillance for hepatocellular carcinoma in 559 hemophiliacs infected with the hepatitis C virus. Blood. 2003;102(1):78-82.

18. Okuda K, Nakashima T, Kojiro M, Kondo Y, Wada K. Hepatocellular carcinoma without cirrhosis in Japanese patients. Gastroenterology. 1989;97(1):140-146.

19. Trevisani F, D'Intino PE, Caraceni P, et al. Etiologic factors and clinical presentation of hepatocellular carcinoma. Differences between cirrhotic and noncirrhotic Italian patients. Cancer. 1995;75(9):2220-2232.

20. Van Roey G, Fevery J, Van Steenbergen W. Hepatocellular carcinoma in Belgium: Clinical and virological characteristics of 154 consecutive cirrhotic and non-cirrhotic patients. Eur J Gastroenterol Hepatol. 2000;12(1):61-66.

21. Fattovich G, Giustina G, Degos F, et al. Morbidity and mortality in compensated cirrhosis type C: A retrospective follow-up study of 384 patients. Gastroenterology. 1997;112(2):463-472.

22. Fattovich G, Pantalena M, Zagni I, et al. Effect of hepatitis B and C virus infections on the natural history of compensated cirrhosis: A cohort study of 297 patients. Am J Gastroenterol. 2002;97(11):2886-2895.

23. El-Serag HB. Hepatocellular carcinoma and hepatitis C in the United States. Hepatology. 2002;36(5 Suppl 1):S74-S83.

24. Nash KL, Woodall T, Woodall T, Brown AS, Davies SE, Alexander GJ. Hepatocellular carcinoma in patients with chronic hepatitis C virus infection without cirrhosis. World $J$ Gastroenterol. 2010;16(32):4061-4065.

25. Fattovich G, Stroffolini T, Zagni I, Donato F. Hepatocellular carcinoma in cirrhosis: Incidence and risk factors. Gastroenterology. 2004; 127(5 Suppl 1):S35-S50.

26. El-Serag HB, Mason AC. Risk factors for the rising rates of primary liver cancer in the United States. Arch Intern Med. 2000;160(21): 3227-3230.

27. Ikeda K, Saitoh S, Arase Y, et al. Effect of interferon therapy on hepatocellular carcinogenesis in patients with chronic hepatitis type $\mathrm{C}$ : A long-term observation study of 1,643 patients using statistical bias correction with proportional hazard analysis. Hepatology. 1999;29(4): 1124-1130.

28. Takano S, Yokosuka O, Imazeki F, Tagawa M, Omata M. Incidence of hepatocellular carcinoma in chronic hepatitis $\mathrm{B}$ and $\mathrm{C}$ : A prospective study of 251 patients. Hepatology. 1995;21(3):650-655. 
29. Velázquez RF, Rodríguez M, Nacascuès CA, et al. Prospective analysis of risk factors for hepatocellular carcinoma in patients with liver cirrhosis. Hepatology. 2003;37(3):520-527.

30. Niederau C, Lange S, Heintges T, et al. Prognosis of chronic hepatitis C: Results of a large, prospective cohort study. Hepatology. 1998;28(6): 1687-1695.

31. Degos F, Christidis C, Ganne-Carrie N, et al. Hepatitis C virus related cirrhosis: Time to occurrence of hepatocellular carcinoma and death. Gut. 2000;47(1):131-136.

32. Serfaty L, Aumaître H, Chazouillères O, et al. Determinants of outcome of compensated hepatitis $\mathrm{C}$ virus-related cirrhosis. Hepatology. 1998;27(5):1435-1440.

33. Lok AS, Seeff LB, Morgan TR, et al. Incidence of hepatocellular carcinoma and associated risk factors in hepatitis C-related advanced liver disease. Gastroenterology. 2009;136(1):138-148.

34. De Mitri MS, Poussin K, Baccarini P, et al. HCV-associated liver cancer without cirrhosis. Lancet. 1995;345(8947):413-415.

35. Raimondi S, Bruno S, Mondelli MU, Maisonneuve P. Hepatitis C virus genotype $1 \mathrm{~b}$ as a risk factor for hepatocellular carcinoma development: A meta-analysis. J Hepatol. 2009;50(6):1142-1154.

36. Fattovich G, Schalm SW. Hepatitis C and cirrhosis. In: Liang TJ, Hoofnagle JH, editors. Hepatitis C. San Diego, CA: Academic Press; 2000.

37. Davila JA, Morgan RO, Shaib Y, McGlynn KA, El-Serag HB. Diabetes increases the risk of hepatocellular carcinoma in the United States: A population based case control study. Gut. 2005;54(4):533-539.

38. Wideroff L, Gridley G, Mellemkjaer L, et al. Cancer incidence in a population-based cohort of patients hospitalized with diabetes mellitus in Denmark. J Natl Cancer Inst. 1997;89(18):1360-1365.

39. Adami HO, Chow WH, Nyrén O, et al. Excess risk of primary liver cancer in patients with diabetes mellitus. J Natl Cancer Inst. 1996;88(20): 1472-1477.

40. El-Serag HB, Davila JA, Petersen NJ, McGlynn KA. The continuing increase in the incidence of hepatocellular carcinoma in the United States: An update. Ann Intern Med. 2003;139(10):817-823.

41. Donato F, Tagger A, Gelatti U, et al. Alcohol and hepatocellular carcinoma: The effect of lifetime intake and hepatitis virus infections in men and women. Am J Epidemiol. 2002;155(4):323-331.

42. Donato F, Gelatti U, Limina RM, Fattovich G. Southern Europe as an example of interaction between various environmental factors: A systematic review of the epidemiologic evidence. Oncogene. 2006;25(27): 3756-3770

43. Lachenmayer A, Alsinet C, Chang CY, Llovet JM. Molecular approaches to treatment of hepatocellular carcinoma. Dig Liver Dis. 2010;42 (Supp1 3):S264-S272.

44. Hoshida Y, Villanueva A, Kobayashi M, et al. Gene expression in fixed tissues and outcome in hepatocellular carcinoma. N Engl J Med. 2008;359(19):1995-2004.

45. Amoroso P, Rapicetta M, Tosti ME, et al. Correlation between virus genotype and chronicity rate in acute hepatitis C. J Hepatol. 1998;28(6): 939-944.

46. Roffi L, Redaelli A, Colloredo G, et al. Outcome of liver disease in a large cohort of histologically proven chronic hepatitis $\mathrm{C}$ : Influence of HCV genotype. Eur J Gastroenterol Hepatol. 2001;13(5):501-506.

47. Nishise Y, Saito T, Sugahara K, et al. Risk of hepatocellular carcinoma and secondary structure of hepatitis $\mathrm{C}$ virus (HCV) NS3 protein aminoterminus, in patients infected with HCV subtype 1b. J Infect Dis. 2007; 196(7):1006-1009.

Hepatic Medicine: Evidence and Research

\section{Publish your work in this journal}

Hepatic Medicine: Evidence and Research is an international, peerreviewed, open access journal covering all aspects of adult and pediatric hepatology in the clinic and laboratory including the following topics: Pathology, pathophysiology of hepatic disease; Investigation and treatment of hepatic disease; Pharmacology of drugs used for
48. Silini E, Bono F, Cividini A, et al. Differential distribution of hepatitis $\mathrm{C}$ virus genotypes in patients with and without liver function abnormalities. Hepatology. 1995;21(2):285-290.

49. Manns MP, McHutchison JG, Gordon SC, et al. Peginterferon alfa-2b plus ribavirin compared with interferon alfa-2b plus ribavirin for initial treatment of chronic hepatitis C: A randomised trial. Lancet. 2001; 358(9286):958-965.

50. Fried MW, Shiffman ML, Reddy KR, et al. Peginterferon alfa-2a plus ribavirin for chronic hepatitis C virus infection. N Engl J Med. 2002; 347(13):975-982.

51. Bruno S, Silini E, Crosignani A, et al. Hepatitis C virus genotypes and risk of hepatocellular carcinoma in cirrhosis: A prospective study. Hepatology. 1997;25(3):754-758.

52. López-Labrador FX, Ampurdanés S, Forns X, et al. Hepatitis C virus (HCV) genotypes in Spanish patients with HCV infection: Relationship between HCV genotype 1b, cirrhosis and hepatocellular carcinoma. J Hepatol. 1997;27(6):959-965.

53. Bruno $\mathrm{S}, \mathrm{Crosignani} \mathrm{A}$, Maisonneuve $\mathrm{P}$, et al. Hepatitis $\mathrm{C}$ virus genotype $1 \mathrm{~b}$ as a major risk factor associated with hepatocellular carcinoma in patients with cirrhosis: A seventeen-year prospective cohort study. Hepatology. 2007;46(5):1350-1356.

54. Donato F, Boffetta P, Puoti M. A meta-analysis of epidemiological studies on the combined effect of hepatitis $\mathrm{B}$ and $\mathrm{C}$ virus infections in causing hepatocellular carcinoma. Int J Cancer. 1998;75(3):347-354.

55. Benvegnù L, Fattovich G, Noventa F, et al. Concurrent hepatitis B and $\mathrm{C}$ virus infection and risk of hepatocellular carcinoma in cirrhosis. A prospective study. Cancer. 1994;74(9):2442-2448.

56. Tsai JF, Jeng JE, Ho MS, et al. Effect of hepatitis C and B virus infection on risk of hepatocellular carcinoma: A prospective study. Br J Cancer. 1997;76(7):968-974.

57. Torbenson M, Thomas DL. Occult hepatitis B. Lancet Infect Dis. 2002;2(8):479-486.

58. Pollicino T, Squadrito G, Cerenzia G, et al. Hepatitis B virus maintains its pro-oncogenic properties in the case of occult HBV infection. Gastroenterology. 2004;126(1):102-110.

59. García-Samaniego J, Rodríguez M, Berenguer J, et al. Hepatocellular carcinoma in HIV-infected patients with chronic hepatitis C. Am J Gastroenterol. 2001;96(1):179-183.

60. Kiyosawa K, Umemura T, Ichijo T, et al. Hepatocellular carcinoma. Recent trends in Japan. Gastroenterology. 2004;127(5 Suppl 1):S17-S26.

61. Di Bisceglie AM, Lyra AC, Schwartz M, et al. Hepatitis C related hepatocellular carcinoma in the United States: Influence of ethnic status. Am J Gastroenterol. 2003;98(9):2060-2063.

62. Donato F, Tagger A, Chiesa R, et al. Hepatitis B and C virus infection, alcohol drinking and hepatocellular carcinoma: A case-control study. Hepatology. 1997;26(3):579-584.

63. Llovet JM, Ricci S, Mazzaferro V, et al. Sorafenib in advanced hepatocellular carcinoma. $N$ Engl J Med. 2008;359(4):378-390.

64. El-Serag HB, Mason AC, Key C. Trends in survival of patients with hepatocellular carcinoma between 1977 and 1996 in the United States. Hepatology. 2001;33(1):62-65.

65. Hoofnagle JH. Hepatocellular carcinoma: Summary and reccomendations. Gastroenterology. 2004;127(5 Suppl 1):S319-S323.

66. Wiesner RH, Freeman RB, Mulligan DC. The impact of the MELD allocation policy. Gastroenterology. 2004;127(5 Suppl 1):S261-S268.

\footnotetext{
Submit your manuscript here: http://www.dovepress.com/hepatic-medicine-evidence-and-research-journal
}

the treatment of hepatic disease. Issues of patient safety and quality of care will also be considered. The manuscript management system is completely online and includes a very quick and fair peer-review system, which is all easy to use. Visit http://www.dovepress.com/ testimonials.php to read real quotes from published authors. 